\title{
The decolonialisation of medicine in South Africa: Threat or opportunity?
}

\begin{abstract}
M de Roubaix
Malcolm de Roubaix is a trained anaesthesiologist who holds a doctorate in Applied Ethics (Bioethics). He is affiliated to the Centre for Medical Ethics and Law, Department of Medicine, Faculty of Medicine and Health Sciences, Stellenbosch University, Tygerberg, Cape Town, South Africa, and is a Fellow of the Centre for Applied Ethics in the Department of Philosophy at the same university. He has a wide interest in bioethics and the ethics of traditional medicine, is passionate about the development of medical ethics and the capacity for ethical argument among medical students and practising medical professionals, and is currently managing the local arm of an international project investigating the social and ethical implications of HIV cure research and cure.
\end{abstract}

Corresponding author: $M$ de Roubaix (malcolmderoubaix@gmail.com)

The South African Traditional Health Practitioners Act 22 of 2007 is now fait accompli. The Act has been promulgated and the Department of Health $(\mathrm{DoH})$ is proceeding with its implementation. An Interim Traditional Health Practitioners Council and a dedicated DoH deputy director have been appointed, the appointment of a registrar is being finalised, and the DoH has conducted a roadshow to introduce the Act and its implications to groups of traditional health practitioners (THPs) countrywide. The objective is eventual formalisation and professionalisation of THP practice to provide appropriate primary healthcare services through co-operation with biomedical service providers. Biomedical practitioners should understand the provisions of Act 22, and how this may affect their own practices.

S Afr Med J 2016;106(2):159-161. DOI:10.7196/SAMJ.2016.v106i2.10371

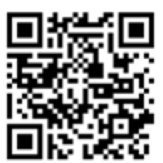

Many aspects of societal and public life are being transformed to an alternative way of believing, thinking and doing; in short, being 'decolonialised. The 'hashtag revolution' has invaded the South African (SA) public space, with political and university terroir in turmoil, and radical change is upon us. Medicine and healthcare delivery will not be spared, although the 'revolution' has remained under the public radar with few reports and commentaries. It is driven not by public outcry, but by an Act of Parliament. This article is a provocative reflection on the implications this has for biomedical practice, though it makes no judgement on the 'legitimacy' of traditional healing.

$\mathrm{We}$, as advocates of biomedicine, have been steeped in a tradition of sound, scientific, evidence-based medicine, believing this to be the only responsible approach to attaining the objectives of medicine - to diagnose, treat and cure if possible, or at least alleviate and console, with compassion and respect. Our belief system conflicts with traditional African cosmology comprising confluent explanations of existence and natural occurrences, of life, religion, health, disease, healing and death. Descriptions or generalisations of African culture and cosmology are bound to be idealised, since Africa is a vast continent with a population of nigh on one billion, more than 50 countries, countless tribes and thousands of languages, ${ }^{[1]}$ and the original descriptions upon which our conceptions of traditional African beliefs emanated from small communities scattered throughout the continent. Yet these descriptions were remarkably similar.

\section{Traditional African cosmology and the role of traditional health practitioners (THPs)}

Traditional African societal structure is summarised in John Mbiti's famous aphorism: 'I am because we are, and because we are, therefore I am, ${ }^{[2]}$ or ' $u b u n t u$ ', made famous by Archbishop Emeritus Desmond Tutu, ${ }^{[3]}$ a unique way of reiterating that no man is an island entirely of itself; when the bell tolls, it tolls collectively for 
humanity. ${ }^{[4]}$ In traditional African thinking, disease may have more direct immediate causes, but often has an ultimate cause, e.g. to be found in some relational disharmony (between individuals in a community, between the patient and some animate or inanimate entity, nature or the ancestors). The diviner (sangoma) determines the nature of disharmony and prescribes corrective measures. But many consultations take place with herbalists who treat a variety of ordinary diseases with natural products. THPs are numerous, ranging from 1:110 of the population (Benin City, Nigeria) to 1:700 1200 (Venda, SA), ${ }^{[5]}$ with a suggested overall sub-Saharan ratio of 1:500. ${ }^{[6]}$ The number of THPs in SA is estimated at $\sim 300000,,^{[7]}$ a ratio of more than 1:170.

THPs are trusted and respected in their communities, culturally embedded, readily available when transport is lacking, and usually less expensive than biomedicine. Peer and family pressure promote their utilisation. Up to $80 \%$ of black South Africans may rely on THPs, even if this is through necessity and they do not utilise THPs preferentially. ${ }^{[8]}$ The 2007 SA traditional medicine (TM) trade was estimated at ZAR2.9 billion. ${ }^{[9]}$ An estimated 5100 full-time THPs practise in the townships of Cape Town and trade about 1300 tons of plant products annually ${ }^{[10]}$ - with a decided environmental impact!

\section{The root of the dillemma}

Whereas biomedical practitioners are steeped in the discourse of evidence-based medicine based on formal studies, the THP exists in a cosmology in which the physical and metaphysical coexist harmoniously. And while the worlds of science and biomedicine have to an extent been opened to the THP, the reverse has not taken place. THPs often combine elements of the biomedical with the traditional. It is difficult for the scientifically trained mind to appreciate the non-standardised and untested, thus unscientific, nature of THP treatments and of the profession. There is evidence that some (Tanzanian) THPs embrace 'modern' approaches, e.g. testing treatments for efficacy and dosage, manufacturing powders and tablets to make medicines last longer than fresh plant products do, and large-scale manufacturing and packaging ${ }^{[1]}$ Reconciling ('proven', in some way or another) herbal treatments with biomedicine may be possible, but 'any approach involving divination and mysticism poses a far greater challenge to the bureaucratic mindset. ${ }^{[7]}$

The two clashing worldviews are characterised respectively by a high level of regulation and formalisation of the biomedical (read: legitimacy) and non-existent regulation and formalisation of the traditional. However, developments aimed at institutionalising and professionalising THPs may help in bridging this divide.

\section{WHO/AU initiatives}

Political advocates of biomedicine have believed that the answer to Africa's medical needs lies in bringing medicine to the people. But globally, in Africa and lately in SA, an alternative approach has developed in recent decades: a return to traditional ways of healing, or, in current terminology, 'decolonialisation' of medicine. The World Health Organization has recognised the legitimacy of traditional approaches to medicine and has proposed measures to promote traditional healing as a profession. ${ }^{[12,13]}$ The African Union (AU) responded by declaring 2001 2010 the Decade of African Traditional Medicine (extended to 2020), ${ }^{[13]}$ and their 2003 action plan promotes this strategy. There has been some progress, e.g. the declaration of 31 August as African Traditional Medicine Day; collaborations and partnerships; and adoption of TM policies, strategic plans and regulatory frameworks by many African countries. AU promotes research on TMs, and training tools have been created. Drawbacks include inadequate funding, human capital and regulatory capacity, lack of evidence of safety and efficacy, and inability to mass-produce medications. ${ }^{[13,14]}$

\section{Locall initiatives}

The SA National Department of Health (DoH) has developed strategies to institutionalise and regulate THPs. The Witchcraft Suppression Act 3 of 1957 (amended 1970) declared TM unlawful. The Traditional Health Practitioners Act 22 of 2007 recognises four THP groupings: diviners, herbalists, traditional birth attendants, and traditional surgeons. ${ }^{[7]}$ In accordance with the Act, an Interim Traditional Health Practitioners Council of SA has been appointed. The Council is directed to advance TM as an acknowledged and esteemed healthcare delivery partner responding to SA's needs. This Council has yet to formalise and operationalise its own structures and will look to the structure/ organisation of the SA Health Professions Council, for example. A registrar should be appointed in 2016, and compulsory registration of THPs (an eventual requisite to practise) will follow. The Act has been much criticised, e.g. for its vagueness on training requirements and regarding the non-scientific approach to disease, research and treatment that it effectively legitimises. ${ }^{[14]}$ Council should eventually be self-funding. The DoH recently conducted a national roadshow to explain Act 22 locally to groups of THPs, and according to the Deputy Director, Traditional Healthcare, DoH (personal communication), found broad and general acceptance of its implications. I was fortunate to attend one of these closed meetings as an observer.

Traditional healing comprises widely divergent practices, treatments and training, so regulating it will be difficult. Current training and licensing of THPs are conducted by approximately 100 THP organisations. The largest umbrella organisation is the cross-border Traditional Healers Organisation (THO), with 25000 SA members. ${ }^{[15]}$

\section{Current initiatives: Lessons from HIV and AIDS care}

Taking HIV and AIDS care as an example, many patients regard biomedicine and TM as equally important, and visit both THPs and clinics before starting on ARVs and even while on ARVs. ${ }^{[16-19]}$ THPs form a 'comprehensive network potentially capable of expanding and simplifying access to comprehensive HIV care through various entry points.[20] Many biomedicine-THP collaborative HIV and AIDS prevention/care programmes are current in Africa (e.g. Swaziland Traditional Healers New Partners Against HIV/AIDS (online: http://www.irinnews.org/ report/32780/swaziland-traditional-healers-new-partners-against-hivaids), Uganda's Traditional and Modern Health Practitioners Together Against AIDS programme, Tanzanias Tanga AIDS Working Group and SA THO programmes $\left.{ }^{[7]}\right)$. In SA, THPs have successfully been integrated into biomedical programmes after undergoing training in HIV prevention strategies, and used to train other THPs; ${ }^{[21]}$ and THPs have been trained/accredited as voluntary counselling and testing counsellors, with positive outcomes. ${ }^{[22]}$ Clinical THP-biomedical co-operation is therefore practicable.

\section{The road forward}

Even if all stakeholders stand to gain by the promotion of the institutionalisation of THPs, ${ }^{[23]}$ it is unclear how this is to be done. A model for integrating THPs into the SA national healthcare delivery system was developed around 'effective communication, mutual respect and trust, reciprocal education and training, two-way referral, scientific testing of TMs. ${ }^{\text {[24] }}$ The THP should eventually be recognised as a fellow professional, and appropriate modules contemplated in undergraduate medical studies. Space would need to be created for THPs within current healthcare structures. Patients should always be provided quality and affordable care, be that by biomedical practitioners or THPs. The DoH aims to promote collaboration, inclusivity (THPs and biomedical practitioners), and broad institutionalisation of THPs, which are the stated aims of Act 22. 
The professionalisation and institutionalisation of THPs will proceed in accordance with the aims of Act 22. At present, biomedicine is sceptical about co-operating with THPs, who are unhappy about the present state of affairs; when compromise is required, it is expected that they perform - never their biomedical counterparts. Perhaps we will also have to learn to compromise; after all, we control both medical discourse and medicine's considerable purse strings. Experience in HIV and AIDS care has shown that co-operation between THPs and biomedicine is possible. Extrapolating this to everyday encounters will be a mammoth task, but there may be no other option.

My hope is that this article will stimulate a proactive debate and co-operation with the THP fraternity to provide the type of healthcare delivery system South Africans deserve, and seem to want. Besides, I doubt that we will be able to barricade ourselves in our ivory towers.

1. Fearon JD. Ethnic and cultural diversity by country. J Econ Growth 2003;8(2):195-222.

2. Mbiti J. African Religions and Philosophies. New York, USA: Doubleday \& Co, 1970:141.

3. Battle M. Reconciliation: The Ubuntu Theology of Desmond Tutu. 2nd ed. Cleveland, Ohio: Pilgrim Press, 2009.

4. Donne J. Meditation XVII. In: Literature Network. http://www.online-literature.co./donne/409/ (accessed 10 November 2015).

5. Chatora R. An overview of the traditional medicine situation in the African region. Afr Health Monit 2003;4(1):4-7.

6. Richter ML. Traditional healing and human rights in South Africa. Poster Exhibition: The XV International AIDS Conference, Bangkok, 11 - 16 July 2004. (Abstract no.: MoPeE4200). https://www.aids2014.org/Abstracts/ A2168031 aspx (accessed 10 November 2015).

7. Flint A, Payne I. Reconciling the irreconcilable? HIV/AIDS and the potential for middle ground between the 7. Flint A, Payne J. Reconciling the irreconcilable? HIV/AIDS and the potential for middle ground between the
traditional and biomedical healthcare sectors in South Africa. Forum Dev Stud 2013;40(1):47-68. [http://dx.doi. traditional and biomedical healthcare
org/10.1080/08039410,2012.702681]

8. Wilkinson K. Do $80 \%$ of South Africans regularly consult traditional healers? The claim is false. Africa Check, 31 July 2013. http://shar.es/lou3U5 (accessed 4 February 2015).

9. Mander M, Ntuli L, Diederichs N, Mavundla K. Economics of the traditional medicine trade in South Africa. S Afr Health Rev 2007;Chap 13:189-196. Health Systems Trust. http://www.hst.org.za/sites/default/files/chap13_07. pdf (accessed 20 March 2015).
10. Petersen L. Cape Town's trade in wild medicines: Ecological threat or essential livelihood resource? Sustainable Livelihoods Foundation, REDI/Econ3x3.January 2014. http://www.econ3x3.org/article/cape-town\%E2\%80\%99strade-wild-medicines-ecological-threat-or-essential-livelihood-resource (accessed 31 July 2015).

11. Marsland R. The modern traditional healer: Locating 'hybridity' in modern traditional medicine, Southern

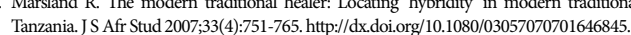

12. World Health Organization. WHO Regional Committee for Africas Resolution AF/RC50/R3. 56th World Health World Health Organization. WHO Regional Committee for Africass Resolution AF/RC50/R3. 56th World Health Assembly, 2003. Report by Secretariat:
ea5618.pdf (accessed 10 March 2015).

13. World Health Organization. WHO Regional Office for Africa 61st Session, September 2011. AFR/RC61/PR/2,
, 5 July 2011. Progress Report on Decade of Traditional Medicine in the African Region. www.afro.who.int/index. php?option=com_docman\&task=doc_download\&gid=6665 (accessed 10 March 2015)

14. Van Niekerk JP. Traditional healers formalised? S Afr Med J 2012;102(8):105-106.

15. Summerton JV. The organisation and infrastructure of the African traditional healing system: Reflections from sub-district of South Africa. Afr Stud 2006;65(2):297-319. [http://dx.doi.org/10.1080/00020180601035708]

16. Mall S. Attitudes of HIV positive patients in SA to African traditional healers and their practices. Cape Town University of Cape Town Centre for Social Science Research: AIDS and Society Research Unit, CSSR Working Paper 215, May 2008.

17. Babb DA, Pemba L,SeatlanyaneS, Charalambous S, Churchyard GJ, Grant AD. Use of traditional medicine by HIVinfected individuals. Psychol Health Med 2007;12(3):314-320. [http://dx.doi.org/10.1080/13548500600621511]

18. Langlois-Klassen D, Kipp W, Jhangri GS, Rubaale T. Use of traditional herbal medicine by AIDS patients in Langlois-Klassen D, Kipp W, Jhangri GS, Rubaale T. Use of traditional he.

19. Peltzer K, Friend-du Preez, Ramlagen S, Fomundam H. Use of traditional complementary and alternative Peltzer K, Friend-du Preez, Ramlagen S, Fomundam H. Use of traditional complementary and alternative
medicine for HIV in KwaZulu-Natal, South Africa. BMC Public Health 2008;8:255. [http://dx.doi. medicine for HIV in KwaZul

20. Homsy J, King R, Balaba D, Kabatesi D. Editorial. Traditional health practitioners are key to scaling up comprehensive care for HIV/AIDS in Sub-Saharan Africa. AIDS 2004;18(12):1723-1725. [http://dx.doi. org/10.1097/01.aids.0000131380.30479.16]

21. Green EC, Zokwe B, Dupree JD. The experience of an AIDS prevention program focused on South African traditional healers. Soc Sci Med 1995;40(4):503-515.

22. Wreford J, Esser M, Hippler S. Involving traditional health practitioners in HIV/AIDS interventions: Lessons from the Western Cape Province In: CSSR Working Paper No. 210. Cape Town: University of Cape Town Centre for Social Science Research, January 2008:6-7.

23. Kofi-Tsekpo M. Institutionalization of African traditional medicine in health care systems in Africa. Afr J Health Sci 2004:11(1-2):i-ii. http://www.ncbi.nlm.nih.gov/pubmed/17298111 (accessed 16 August 2015).

24. Pinkoane MG, Greeff M. Koen MP. A model for the incorporation of the traditional healers into the national 24. Pinkoane MG, Greeff M, Koen MP. A model for the incorporation of the traditional healers into the national
healthcare delivery system of South Africa. Afr J Complement Alt Med 2012;9(Suppl 3):12-18. [http://dx.doi. org/10.4314/ajtcam.v9i3s.2]

Accepted 2 December 2015. 